\title{
Projected changes in age-related macular degeneration and driving license holders in Finland
}

This article was published in the following Dove Press journal:

Clinical Ophthalmology

22 September 2014

Number of times this article has been viewed

\section{Olli Viitanen' \\ Olli Arjamaa ${ }^{2}$}

'Department of Ophthalmology, University Central Hospital of Turku, Turku, Finland; ${ }^{2}$ Department of Biology, University of Turku,

Turku, Finland
Correspondence: Olli Arjamaa

Department of Biology, Vesilinnanties 5, 20014 University of Turku, Turku, Finland Tel +358405I25452

Email olli.arjamaa@utu.fi
Purpose: The aim of the study was to approximate the occurrence of all forms of age-related macular degeneration (AMD) of the retina among the driving license holders aged 80 or more, and to project the changes to 2030 in Finland. AMD, destroying the visual cells in the central part of the retina, is a common disease of older age: one out of three individuals aged 70 or older shows early signs of AMD progressing later to relentless loss of vision. This eye disease can be detected only by an ophthalmologist. In general, little is known about the prevalence of AMD among driving license holders aged 80 or older.

Methods: At first the prevalence of individuals with either drusen or AMD in Finland among those 80 or older was approximated. Then the number of license holders in this age group was extracted from the statistics of the Finnish Transport Safety Agency and Eurostat provided us with the demographical data. The changes were projected to 2030.

Results: In Finland, with a population of 5.35 million, the number of those aged 80 or over will increase by 175,000 by 2030 . The total number of individuals with either drusen or AMD will increase from 118,000 to 193,000 by the year 2030 and an increasing proportion of them will have a driving license. The proportion of women in 2012 having a driving license in the groups 60 or younger is about $45 \%$, while in those aged 80 or older it is only $20 \%$.

Conclusion: The number of people aged 80 years or older will increase in Finland by 2030. The number of those in this age group having a driving license will increase more rapidly as the population ages because the proportion of women with a driving license will increase in this age group. As the prevalence of drusen and AMD among women aged 80 or over is higher than among men at comparable age, this means that AMD will increase even more rapidly among drivers in this age group.

Keywords: age-related macular degeneration, AMD, retina, driving license holders, Finland

\section{Introduction}

Aging has become a noticeable phenomenon in developed countries. On average, the population aged between 65 and 74 years will double between 1950 and 2050, and the number of people over 75 years old has been estimated to increase over five times during the same period in western countries. ${ }^{1}$ As the population ages, the prevalence of severe visual problems is increasing: one out of three individuals aged 70 or older shows early signs of age-related macular degeneration (AMD) of the retina, progressing later to severe forms of degeneration and demonstrating relentless loss of vision..$^{2-5}$ Other retinal diseases, due to the obesity epidemic, also increase with age. The dry form of AMD, in which retinal cells slowly deteriorate in the central part of the retina, accounts for $80 \%-90 \%$ of cases. In the wet form, the loss of vision which can occur within a few weeks, is caused by new vessels (neovascularization) under the retina. These new vessels are fragile; without the support of smooth muscle 
cells they leak blood and fluid, causing scarring in the middle of the retina. In addition, $10 \%-20 \%$ of the dry form of AMD, may later become wet. ${ }^{6}$ The 15 year cumulative incidence of the end stages of AMD in individuals 75 years of age or older was $8 \%{ }^{7,8}$ and in a small Finnish sample of a population aged 70 and older, early signs of age-related maculopathy occurred in $41 \%$ of patients examined..$^{9}$ In the United Kingdom, 192,000 people aged 75 years or older are visually impaired due to severe forms of AMD. ${ }^{10}$ AMD affected more than 1.75 million individuals in the United States in 2004 and this figure will increase to almost 3 million in 2020. ${ }^{11}$ However, the prevalence of patients becoming eligible for blindness certification due to the wet form of AMD may decrease in the future because of the introduction of intravitreal anti-vascular endothelial growth factor injections. ${ }^{12,13}$ In general, AMD, being a complex multifactorial disease, can powerfully reduce the ability to drive a motor vehicle ${ }^{14,15}$ and yet, unlike neurological or orthopedic problems, remain unnoticed by traffic authorities. A possible eye disease and its severity can be observed only by an ophthalmologist.

Little is known about the prevalence of eye diseases among older drivers in European countries. There are no comparable data available on driving license holders and their eye diseases at older age in the member states of the EU.

Here, the data from The Finnish Transport Safety Agency ${ }^{16}$ on driving license holders, aged 80 or more, were connected to the prevalence of drusen, dry and wet form of AMD ${ }^{11}$ and to the demographic changes in Finland, and forecasted through the year $2030 .^{18}$

\section{Methods}

The Finnish Transport Safety Agency ${ }^{16}$ provided us with the number of valid driving licenses by sex and 5 year age groups starting at the age of 15 up to the age of 100 and over. The prevalence of all types of macular degeneration (drusen, dry and exudative) in Finland among those 80 and over and representing a homogeneous white population was approximated from a previously published study in the United States by age, race/ethnicity, and sex. ${ }^{11}$ Then, the proportion of those aged 80 or over by sex in Finland was projected to the year $2030,{ }^{17}$ and the prevalence of AMD and driving license holders by sex was approximated for that year among this population. In both cases it was assumed that the rates will not change from now until 2030.

\section{Results and discussion}

The population of Finland in 2010 was 5.35 million and it will grow to 5.70 million by 2030 (Eurostat website). ${ }^{17}$
The population aged 80 years or more in 2015 will, according to Eurostat, increase by 175,000 by the year 2030 and, accordingly, during the same period of time, the prevalence of all types of AMD (drusen, dry and wet form) is also expected to increase (Figure 1). When analyzing the changes per sex, noticeable differences can be found. The prevalence of all types of AMD in females aged 80 or more will be higher than in males at a comparable age as approximated from published figures. ${ }^{11}$ The proportion of females also continues to be higher in this age group, although it is expected to decrease from $66.5 \%$ to $61.4 \%$ by 2030 (Eurostat website). The number of females with all forms of AMD will thus increase from 84,000 to 127,000 between 2015 and 2030, and in males from 34,000 to 66,000 in Finland (Figure 2A and B).

According to the Finnish Transport Safety Agency, ${ }^{16}$ the number of valid driving licenses among those aged 80 or more (women and men) increased greatly between 2001 and 2009; the figure more than doubled from 23,000 to 48,500 (Figure 3A). Among women the increase was almost 3-fold and among men the increase was 2-fold during the same period of time. The proportion of female driving license holders increased from $14.7 \%$ to $20.8 \%$ in this age group (Figure 3A). Figure 3B shows the number of driving license holders by age and sex in 2012 .

The sex ratio among driving license holders in 2012 in different age groups shows that the proportion of males is

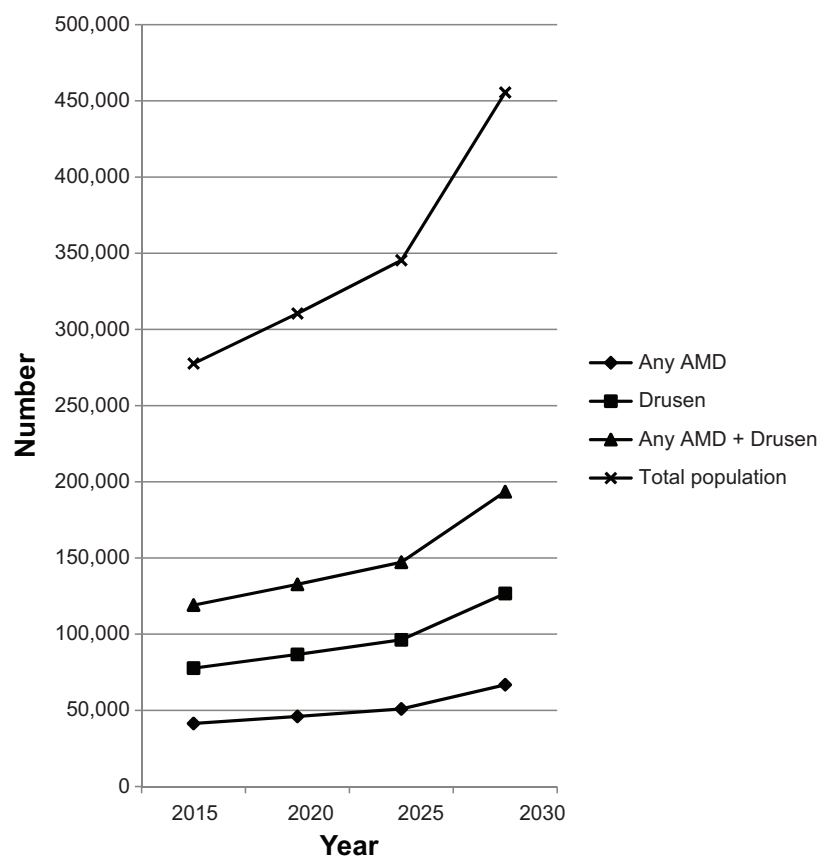

Figure I Projected changes in the population and in the prevalence of age-related macular degeneration (AMD) of the retina in Finland among those aged 80 years or older.

Notes: Any AMD; dry and wet form of AMD. Drusen; early signs of macular degeneration. 
A

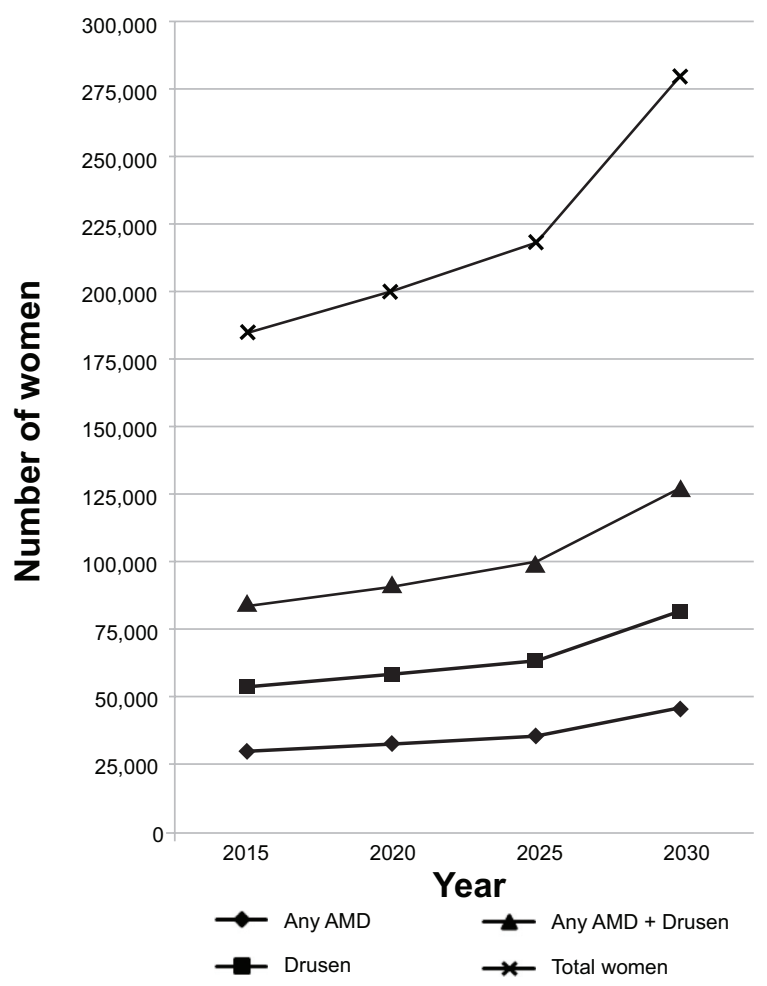

B

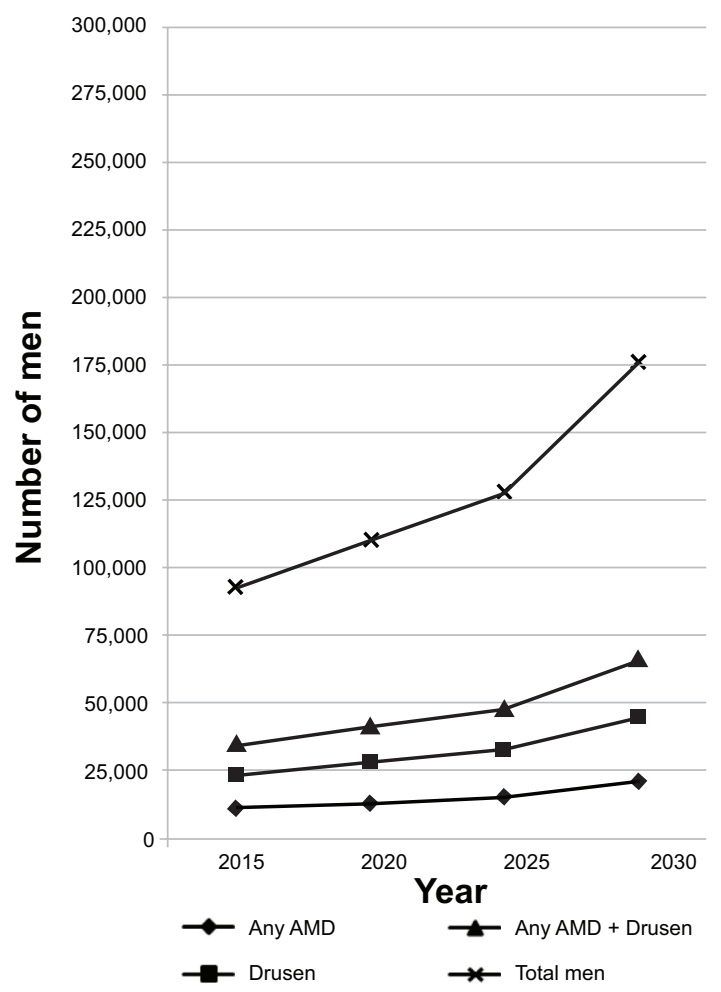

Figure 2 Projected changes in the number of women (A) and men (B) aged 80 years or older and the prevalence of age-related macular degeneration (AMD) of the retina in Finland.

Notes: Any AMD; dry and wet form of AMD. Drusen; early signs of macular degeneration.

higher in every age group and that the male dominance grows larger beyond the age of 60 (Figure 4); at the same time point among the drivers younger than 60 , the proportion of females is almost $50 \%$, while among those aged 80 or older it is $20 \%$ or less (Figure 4 ).

The population of Finland is aging as in other western countries; the diseases associated with aging are therefore also increasing. The number of women over 80 is growing more rapidly in the population than the number of men in the same age group. The prevalence of AMD of the retina, affecting visual activity, increases rapidly beyond the age of 75 . During the past decade, the number of female drivers aged 80 or more increased in Finland 3-fold, while the increase among men was only 2 -fold. The distribution of driving licenses

B

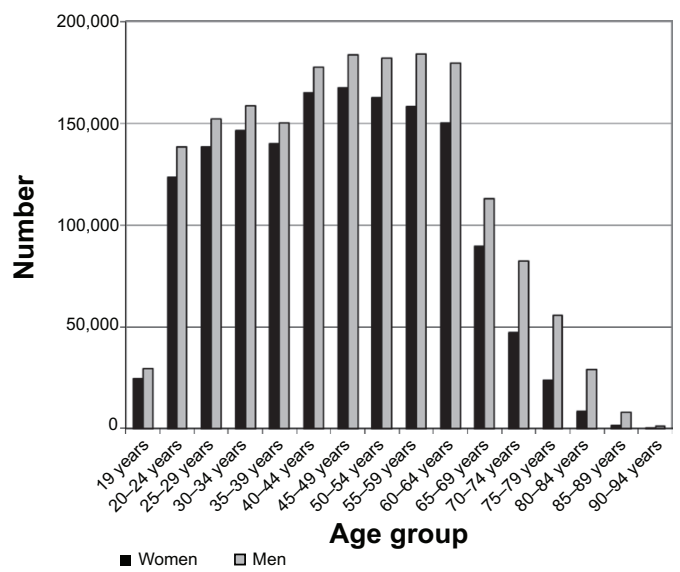

Figure 3 Driving license holders in Finland by sex from 2001 to 2009 among those aged 80 years or older (A) and in 2012 (B) in different age groups. 


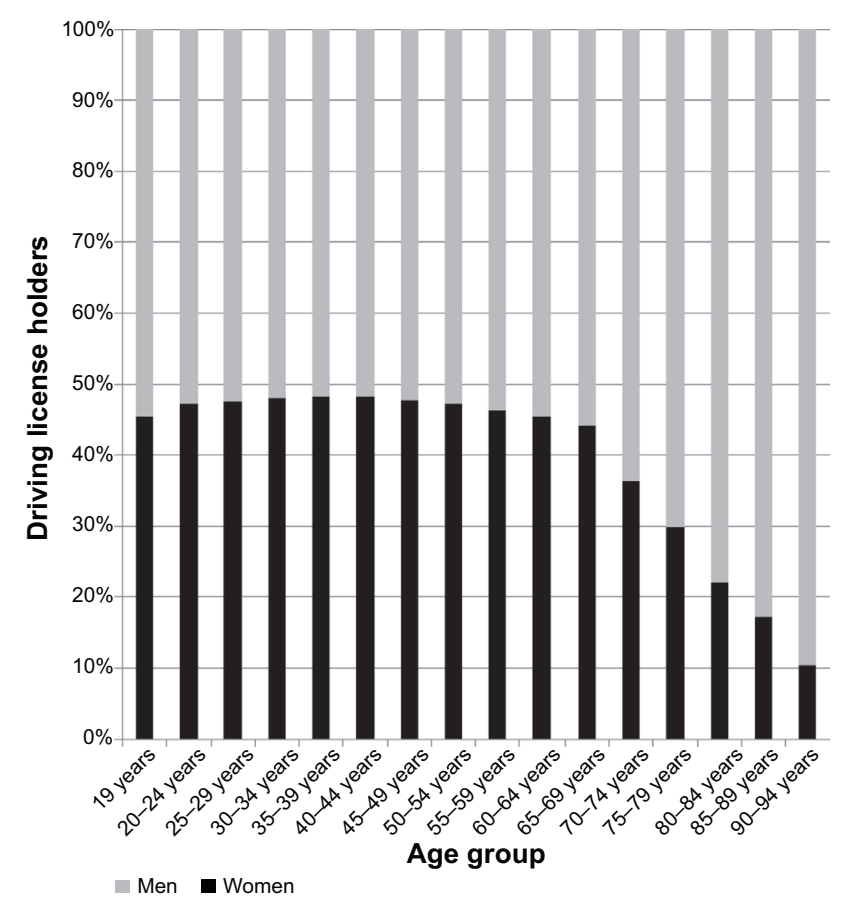

Figure 4 Sex ratio of driving license holders and age in 2012 in Finland.

by sex and age, analyzed in 2011, shows that the proportion of female driving license holders is almost $50 \%$ in the age groups younger than 60 , while the proportion is about $20 \%$ in the age group 80 and over. This means that the number of driving license holders at the age of 80 or over will increase in the future more quickly than the population aging rate would suggest. The number of driving license holders in 1980, aged 60 or over in Finland was 135,658, while in 2004, the number was 591,271 , corresponding to a 4.4 -fold increase. ${ }^{18}$ As per sex, the change in male drivers increased 3.2-fold, while in female drivers the change was 10.6-fold over the same period of time ${ }^{18}$ It follows that the prevalence of AMD among older drivers will thus increase as projected to 2030, especially due to the older female drivers whose proportion will increase. The prevalence of AMD, however, was calculated in this study from prevalence figures of whites, which are higher than those of blacks. ${ }^{11}$ In comparison, a large increase in license holding by both men and women aged 70 and over since 1975, has also been recorded in the United Kingdom ${ }^{19}$ where currently $2.3 \%$ of the population is aged 85 or over. ${ }^{20}$

It is, however, unclear how AMD eventually affects the accident involvement rate among older drivers. It has been suggested that as driving appears to involve a complex set of skills, it needs to be considered in the context of the driver's overall health and other functional abilities among which AMD is only one parameter. ${ }^{21,22}$ Contrary to default expectations, older drivers with intermediate AMD were found to have a reduced risk of collision involvement in one small study. ${ }^{23}$
Also, self-regulatory driving practices may change at older age $;{ }^{24}$ for example, drivers reduce their mileage as they age and avoid driving in the dark, as well as using routes well-known to them with the result that they have fewer accidents than their younger counterparts. ${ }^{19}$ Additionally, men are more likely to be behind the steering wheel at an older age than females ${ }^{25}$ who have a higher prevalence of AMD, thus distorting the conclusions drawn from the sex distribution of license holders. According to an opinion poll measuring society's attitudes toward risk factors in traffic, drunk-drivers were regarded as far more dangerous than older drivers who were considered no greater threat to other road users than younger drivers; however, older drivers are at risk to themselves because of their higher fragility. ${ }^{20}$ Careful planning of urban and recreational areas with better public commuting systems may decrease the need for a motor vehicle in households in the future.

According to Desapriya et $\mathrm{a}^{26}$ no such randomized controlled studies have been published on vision screening tests and their effects on the reduction of subsequent motor vehicle crashes, road traffic injuries or fatalities, that would fulfill the inclusion criteria for a Cochrane Database analysis. Current vision screenings, based on visual acuity only, may exclude important aspects of visual impairment such as useful field of view, glare, loss of visual field, static or dynamic acuity, and contrast sensitivity; ${ }^{27,28}$ so future directions for studying the visual competence among older drivers with AMD are urgently needed to find the best balance between safety and independence during successful ageing. ${ }^{29}$ In 2013 medical examinations have not been shown to have any effect on the overall road safety of people aged 65 or over when they are either acquiring or renewing their driving license. ${ }^{19}$

The total burden on society of AMD alone is large and is expected to grow. Specifically, the occurrence of AMD among older drivers has not been previously evaluated in a single country because of lacking statistics. In addition, macular degeneration often occurs in combination with other hidden diseases such as diabetic retinopathy and dementia, reducing the visual capacity of drivers, and changing their behavior in traffic in an unpredictable manner. The world prevalence of diabetes among adults was 285 million in 2010 and will be 439 million in 2030, ${ }^{30}$ while the global prevalence of dementia which in 2014 is as high as 24 million will quadruple by the year $2050 .{ }^{31}$ The high number of older people with an eye disease alone or in combination with additional diseases and still active behind the steering wheel calls for improved detection and follow-up systems of visual functions. Moreover, there is a general need to have information on the driving license holders, by age and sex, for the development of cost and 
safety effective screening systems of the visual capacity of older drivers.

\section{Acknowledgments}

The authors acknowledge a proportion of the financial support from the Department of Ophthalmology, University Central Hospital of Turku and the Department of Biology, University of Turku, Finland.

\section{Disclosure}

The authors declare no conflicts of interest in this work.

\section{References}

1. Doyle YG, McKee M, Sherriff M. A model of successful ageing in British populations. Eur J Publ Health. 2010;22(1):71-76.

2. Fine SL, Berger JW, Maguire MG, Ho AC. Age-related macular degeneration. $N$ Engl J Med. 2000;342(7):483-492.

3. Mukesh BN, Dimitrov PN, Leikin S, et al. Five-year incidence of agerelated maculopathy: the Visual Impairment Project. Ophthalmology. 2004;111(6):1176-1182.

4. Ambati J, Fowler BJ. Mechanisms of age-related macular degeneration. Neuron. 2012;75(1):26-39.

5. Chew EY, Clemons TE, Agrón E, et al. Ten-year follow-up of agerelated macular degeneration in the age-related eye disease study: AREDS Report No 36. JAMA Ophthalmol. 2014;132(3):272-277.

6. Ehrlich R, Harris A, Kheradiya NS, Winston DM, Ciulla TA, Wirostko B. Age-related macular degeneration and the aging eye. Clin Interv Aging. 2008;3(3):473-482.

7. Klein R, Klein BE, Knudtson MD, Meuer Sm, Swift M, Gangnon RE. Fifteen-year cumulative incidence of age-related macular degeneration: the Beaver Dam Eye Study. Ophthalmology. 2007;114(2): 253-262.

8. Klein R, Cruickshanks KJ, Nash SD, et al. The prevalence of age-related macular degenera tion and associated risk factors. Arch Ophthalmol. 2010;128(6):750-758.

9. Laatikainen L, Hirvelä H. Prevalence and visual consequences of macular changes in a population aged 70 years and older. Acta Ophthalmol Scand. 1995;73(2):105-110.

10. Evans JR, Fletcher AE, Wormald RP. Age-related macular degeneration causing visual impairment in people 75 years or older in Britain: an add-on study to the Medical Research Council Trial of Assessment and Management of Older People in the Community. Ophthalmology. 2004;111(3):513-517.

11. Friedman DS, O'Colmain BJ, Munoz B, et al. Prevalence of age-related macular degeneration in the United States. Arch Ophthalmol. 2004; 122(4):564-572.

12. Rein DB, Wittenborn JS, Zhang X, et al. Forecasting age-related macular degeneration through the year 2050: The potential impact of new treatments. Arch Ophthalmol. 2009;127(4):533-540.

Clinical Ophthalmology

\section{Publish your work in this journal}

Clinical Ophthalmology is an international, peer-reviewed journal covering all subspecialties within ophthalmology. Key topics include: Optometry; Visual science; Pharmacology and drug therapy in eye diseases; Basic Sciences; Primary and Secondary eye care; Patient Safety and Quality of Care Improvements. This journal is indexed on
13. Keenan TD, Kelly SP, Sallam A, Mohamed Q, Tufail A, Johnston RL Incidence and baseline clinical characteristics of treated neovascular age-related macular degeneration in a well-defined region of the UK. Br J Ophthalmol. 2013;9(9)7:1168-1172.

14. Coeckelbergh TR, Brouwer WH, Cornelissen FW, Van Wolffelaar P, Kooijman AC. The effect of visual field defects on driving performance: a driving simulator study. Arch Ophthamol. 2002;120(11):1509-1516.

15. Bronstad PM, Bowers AR, Albu A, Goldstein R, Peli E. Driving with central field loss I: Effect of central scotomas on responses to hazards. JAMA Ophthalmol. 2013;131(3):303-309.

16. Finnish Transport Safety Agency [homepage on the Internet]. Finnish Transport Safety Agency Statistics. Available from: http://www.trafi. fi/en/services/statistics. Accessed April 2011.

17. Eurostat [homepage on the Internet]. Population statistics. Available from: http://epp.eurostat.ec.europa.eu/portal/page/portal/population/ data/database. Accessed April 2011

18. Arjamaa O. Eye diseases among elderly drivers in Finland. Eur J Publ Health. 2006;16(4):446-447.

19. Mitchell CG. The licensing and safety of older drivers in Britain. Acc Anal Prev. 2013;50:732-741.

20. Robertson R, Vanlaar W. Elderly drivers: future challenges? Acc Anal Prev. 2008;40(6):1982-1986.

21. Hakamies-Blomqvist L, Peters B. Recent European research on older drivers. Acc Anal Prev. 2000;32(4):601-607.

22. Bohensky M, Charlton J, Odell M, Keeffe J. Implications of vision testing for older driver licensing. Traffic Inj Prev. 2008;9(4):304-311.

23. McGwin G Jr, Mitchell B, Searcey K, et al. Examining the association between age-related macular degeneration and motor vehicle collision involvement: a retrospective study. Br J Ophthalmol. 2013;97(9): $1173-1176$

24. Sengupta S, van Landingham SW, Solomon SD, Do DV, Friedman DS, Ramulu PY. Driving habits in older patients with central vision loss. Ophthalmology. 2014;121(3):727-732.

25. Sivak M. Female drivers in the United States, 1963-2010 from minority to a majority? Traffic Inj Prev. 2013;14(3):259-260.

26. Desapriya E, Wijeratne H, Subzwari S, et al. Vision screening of older drivers for preventing road traffic injuries and fatalities. Cochrane Database Syst Rev. 2011;(3):CD006252.

27. Currie Z, Bhan A, Pepper I. Reliability of Snellen charts for testing visual acuity for driving: prospective study and postal questionnaire. BMJ. 2000;321(7267):990-992.

28. Rubin GS, Ng ES, Bandeen-Roche K, Keyl PM, Freeman EE, West SK. A prospective, population-based study of the role of visual impairment in motor vehicle crashes among older drivers: the SEE study. Invest Ophthalmol Vis Sci. 2007;48(4):1483-1491.

29. Fildes BN. Future directions for older driver research. Traffic Inj Prev. 2008;9(4):387-993.

30. Shaw JE, Sicree RA, Zimmet PZ. Global estimates of the prevalence of diabetes for 2010 and 2030. Diab Res Clin Pract. 2010;87(1):4-14.

31. Reitz C, Mayeux R. Alzheimer disease: Epidemiology, diagnostic criteria, risk factors and biomarkers. Biochem Pharmacol. 2014;88(4): 640-651.
PubMed Central and CAS, and is the official journal of The Society of Clinical Ophthalmology (SCO). The manuscript management system is completely online and includes a very quick and fair peer-review system, which is all easy to use. Visit http://www.dovepress.com/ testimonials.php to read real quotes from published authors. 